\title{
CORRIGENDUM
}

\section{Simultaneous detection of NPM1 and FLT3-ITD mutations by capillary electrophoresis in acute myeloid leukemia}

NI Noguera, E Ammatuna, D Zangrilli, S Lavorgna, M Divona, F Buccisano, S Amadori, C Mecucci, B Falini and F Lo-Coco

Leukemia (2007) 21, 1135. doi:10.1038/sj.leu.2404664

Correction to: Leukemia (2005) 19, 1479-1482.

doi:10.1038/sj.leu.2403846

It has been identified by the authors that there is an error in the sequence of primers used for FLT3 amplification (Table 1).
The correct sequence is as follows:

The authors apologize for any inconvenience caused.

Table 1

\begin{tabular}{|c|c|c|c|c|c|}
\hline Name & Sequence & Dye & Position & Accession number & PCR (product size) \\
\hline $\begin{array}{l}\text { (D3)ITD-R6 } \\
\text { R5-ITD }\end{array}$ & $\begin{array}{l}5^{\prime} \text {-atcctagtaccttcccaaactc- } 3^{\prime} \\
5^{\prime} \text {-tatcgagcagtactctaaaca- } 3^{\prime}\end{array}$ & D3 & $\begin{array}{l}1913-1934 \\
1569-1589\end{array}$ & $\begin{array}{l}\text { NM_004119 } \\
\text { NM_004119 }\end{array}$ & Flt3-ITD (366 bp) \\
\hline
\end{tabular}

